\title{
TRADUÇÃO DOS SINAIS-TERMOS DAS EXPRESSÕES REGIONAIS DE SANTARÉM/PA E BOA VISTA/RR
}

\author{
THE SIGNS-TERMS OF SANTARÉM / PA AND \\ BOA VISTA REGIONAL EXPRESSIONS / RR
}

http://lattes.cnpq.br/5535862195916827

\section{Luciano Bruno dos Santos Lobato 2 \\ http://lattes.cnpq.br/8198676442666809}

Lucas Nascimento ${ }^{3}$

http://lattes.cnpq.br/4176639401617663

https://orcid.org/0000-0003-4627-8991

Enviado em: 01/06/2020

Aceito em: 25/09/2020

\begin{abstract}
RESUMO: Este trabalho tem como objetivo catalogar e registrar sinais-termos das expressões dialetais de duas comunidades surdas do norte, Boa vista-Roraima e Santarém-Pará. A pesquisa vem se desenvolvendo através de aproximações, pesquisa etnográfica e eliciação com sinalizantes surdos e não surdos através da observação participante junto a estas comunidades, a fim de se obter um embasamento reflexivo acerca da questão de o porquê os surdos se empenharem tanto em "traduzir", ou seja, criar um sinal específico para as expressões dialetais e até mesmo para as expressões sonoras próprias da cultura falada do norte, a exemplo de ÉGUA e TÉDOIDÉ. A catalogação dos referidos sinais-termos envolve uma reflexão acerca dos aspectos sociolinguísticos destas comunidades. Diante dos termos já registrados e das observações etnográficas, percebemos o quanto, para essas duas comunidades surdas, é importante e recorrente o uso de tais expressões na sinalização cotidiana, principalmente, na interação surdo-ouvinte.
\end{abstract}

Palavras-Chave: Libras; Terminologia; Expressões regionais.

ABSTRACT: This work aims to catalog and record signs-terms of the dialectal expressions of two deaf communities of the north, Boa Vista-Roraima and Santarém-Pará. Research has been developing through approaches, ethnographic research, and elicitation with deaf and non-deaf "signalizer" through participant observation with these communities, in order to obtain a reflective basis on the question of why the deaf engage in both " translate ", that is, to create a specific sign for the dialectal expressions and even sound expressions typical of the culture spoken in the north of Brazil, such as ÉGUA and TÉDOIDÉ. The cataloging of these sign-terms involves a reflection on the sociolinguistic aspects of these communities. In view of the already recorded terms and ethnographic observations, we perceive the use of such expressions in everyday signaling, especially in the deaf-hearer interaction, for these two deaf communities.

1 Professora efetiva do Curso Letras Libras Bacharelado da Universidade Federal de Roraima-UFRR. Mestra em Estudos da Tradução pela Universidade de Brasília-UnB. Líder do Grupo de Estudos e Pesquisas em Tradução e Interpretação Intermodal-Tradlln/UFRR. E-mail: thaisybentes@hotmail.com

2 Tradutor e Intérprete de Libras/Português. Atual coordenador do Núcleo de Apoio às Pessoas com Necessidades Específicas - NAPNE, do Instituto Federal do Mato Grosso-IFMT/campus Confresa. E-mail: Iucianolobatolibras@gmail.com

${ }^{3}$ Doutor em Linguística pela Universidade Federal do Rio de Janeiro-UFRJ (FAPERJ/Bolsa Nota 10). Realizou estágio de pesquisa em Estocolmo (Suécia), pela Stockholm University, sobre português língua materna, sueco segunda língua e bilinguismo (português-sueco). Pós-doutorado pela Universidade Federal de Roraima-UFRR. E-mail: drlucasdonascimento@gmail.com 
Key Words: Libras; Terminology; Regional expressions.

\section{Introdução}

Os estudos que se dedicam às línguas de sinais, desde Stokoe (1960), têm se ocupado bastante em descrevê-las, a fim de provar e reforçar seu estatuto de língua. Recentemente, com o mesmo objetivo, os estudos léxicos-terminológicos sobre as LSs ganharam força à medida que pesquisadores buscam desenvolver projetos na área, principalmente pesquisadores de pós-graduações, no Brasil. Trabalhos como de Faulstich (1997; 2014; 2016), Felten (2016) e Tuxi (2017) inauguram metodologias e novos modelos de catalogar e registrar os termos da/na Libras, além de criarem novas perspectivas teóricas para/sobre a área.

A "colheita" desses termos não é recente. Desde 2014, temos nos inclinado sobre termos "marginais", aqueles considerados "à parte" da língua, fenômenos menos vistos, menos estudados e menos reconhecidos como parte da linguagem, porém usados cotidianamente, principalmente, na oralidade e na informalidade. Falamos de trocadilhos, palavrões, termos obscenos, eróticos e regionalismos, foco deste trabalho. Os surdos (cabocos-amazônidas-nortistas) inseridos nestas culturas absorvem e são absorvidos pela linguagem regional.

Desse modo, o objetivo deste trabalho se restringe apenas a apresentar uma parte da pesquisa ${ }^{4}$ desenvolvida desde 2014 sobre os termos marginais nas línguas de sinais. Para organização, apresentaremos primeiramente um breve panorama dos estudos léxico-terminológicos da/na Libras (Língua Brasileira de Sinais). Posteriormente, aspectos culturais e regionais das duas comunidades surdas pesquisadas e a metodologia da pesquisa. E por fim, as análises dos registros dos sinais-termos regionais, seguido das considerações finais.

\section{Estudos léxicos e terminológicos sobre/das línguas de sinais}

As línguas de Sinais - LS eram consideradas mímicas e/ou pantomimas (até hoje são entendidas assim por quem não conhece), haja vista que não havia estudos sobre o funcionamento das estruturas gramaticais/lexicais, e seus falantes eram tidos como invisíveis por ter um número de nativos inferior ao do idioma de seu país. A partir das pesquisas realizadas por Wilian Stokoe (1960), sobre a American Sign Language- ASL, surge novas perspectivas sobre a linguística das línguas sinalizadas.

Os estudos iniciais de Stokoe proporcionaram e comprovaram que as línguas de sinais atendiam a todos os critérios linguísticos de uma língua genuína. Com esse primeiro "atrevimento", aspectos que até então ainda não tinham sido notados nas LSs, como léxico, sintaxe e demais elementos gramaticais foram estudados e comparados aos estudos das línguas orais, comprovando semelhanças e diferenças, estas últimas ocasionadas pela mudança modal de produção.

Segundo Tuxi (2017), as línguas minoritárias manifestam em si conceitos constantemente contrastivos à língua majoritária, em especial, no tocante aos estudos científicos dos termos dessas línguas. $\mathrm{Na}$ Libras ocorre o mesmo processo, considerando que esta tem um número reduzido de falantes e que em seu país a língua majoritária é a língua portuguesa, necessitando assim de mais pesquisas e reflexões, além da criação, registro e catalogação de novos sinais-termos, os quais são divergentes nas suas áreas de conhecimento. Os estudos terminológicos e lexicais vêm ganhando espaço em diversas pesquisas concernentes aos Estudos de Tradução, tendo em vista que tais estudos são fundamentais para o desenvolvimento e consolidação da área e para corroborar as LSs como Línguas das comunidades surdas.

\footnotetext{
4 Desenvolvida no âmbito do Grupo de Estudos e Pesquisas de Tradução e Interpretação Intermodal-TradlIn, da Universidade Federal de Roraima, em parceria com o Grupo de Pesquisa em Educação Especial e Processos Inclusivos-GPEEPI, da Universidade Federal do Oeste do Pará.
} 
Segundo Faulstich (2003), a terminologia é o campo da ciência que estuda o léxico de especialidade, por meio dos mecanismos que evidenciam os princípios linguísticos. Percebemos o quanto se faz necessárias pesquisas no campo lexical e terminológico dentro das línguas, pois este campo está presente nos processos e estudos tradutórios, interpretativos e linguísticos.

Conforme Tuxi (2017),

Nas línguas orais, o objeto de estudo da Terminologia é o termo. Nas línguas de sinais, consagrou-se, com base na proposta de Faulstich (2016), o signo linguístico sinal-termo, como objeto de estudo da Terminologia nas Línguas de Sinais. Essa proposta foi postulada com base no fato de que o signo-linguístico que compõe o sinal-termo nas línguas de sinais se constitui pela abstração mental do conceito e significado que o objeto representa na mente do interpretante, no caso o surdo, e no fato de que na língua de sinais há uma diferença entre sinais usados na linguagem comum e nas linguagens de especialidade (TUXI, 2017, p. 20).

A busca de espaço dentro da área da terminologia é o início das lutas e movimentos para ganhar reconhecimento dentro dos estudos linguísticos gerais, fomentando cada vez mais que os sujeitos surdos façam parte da sociedade, que percebam e participem das discussões de todas as áreas por meio da sua própria língua, ou seja, a Libras.

Vejamos que

A denominação sinal-termo, proposta conceitual criada por Faulstich (2012), teve origem durante orientação de mestrado de Messias Costa (2012): Durante as discussões de natureza lexicográfica, Faulstich percebeu que a expressão sinal ou sinais não correspondia ao significado de termos usados no contexto das linguagens de especialidade, especialmente na terminologia científica ou técnica. A designação sinal serve para os significados usados no vocabulário comum da Libras, enquanto sinal-termo para as linguagens de especialidade (FAULSTICH, 2016, p. 5).

Para composição-criação de novos sinais ou sinais-termos, Faria-Nascimento (2009, p. 108) considera que o léxico da Libras é constituído pelos seguintes elementos: parâmetros, classificadores, empréstimos linguísticos, elementos prototípicos e morfemas-base. "Nesse sentido, o processo de criação do sinal-termo advém da necessidade de a língua representar elementos complexos como são os da linguagem de especialidade e, desse modo, preencher lacunas" (VALE, 2018, p. 31).

Tuxi (2017) realiza um levantamento de trabalhos, de 2007 a 2016, desenvolvidos com essa temática (Gráfico 1). Entre elas, identificamos duas pesquisas relacionadas ao tema aqui abordado, expressões regionais, ou que se aproximam: "Diversidade Linguístico-Cultural da Língua de Sinais do Ceará: Um Estudo Lexicológico das Variações da Libras na Comunidade de Surdos do Sítio Caiçara" e "Variações regionais na Língua de Sinais Brasileira: interiorizando a prática educativa". De 2016 a 2018, não encontramos pesquisas ${ }^{5}$ que abordem a temática da tradução, registro de sinais-termos de expressões regionais.

\footnotetext{
${ }^{5}$ Pesquisa não aprofundada, realizada apenas no catálogo de teses e dissertações da CAPES e em alguns periódicos online.
} 
Gráfico 1 - Estudos do léxico e terminologia da LSB - Da iniciação científica a pós-graduação

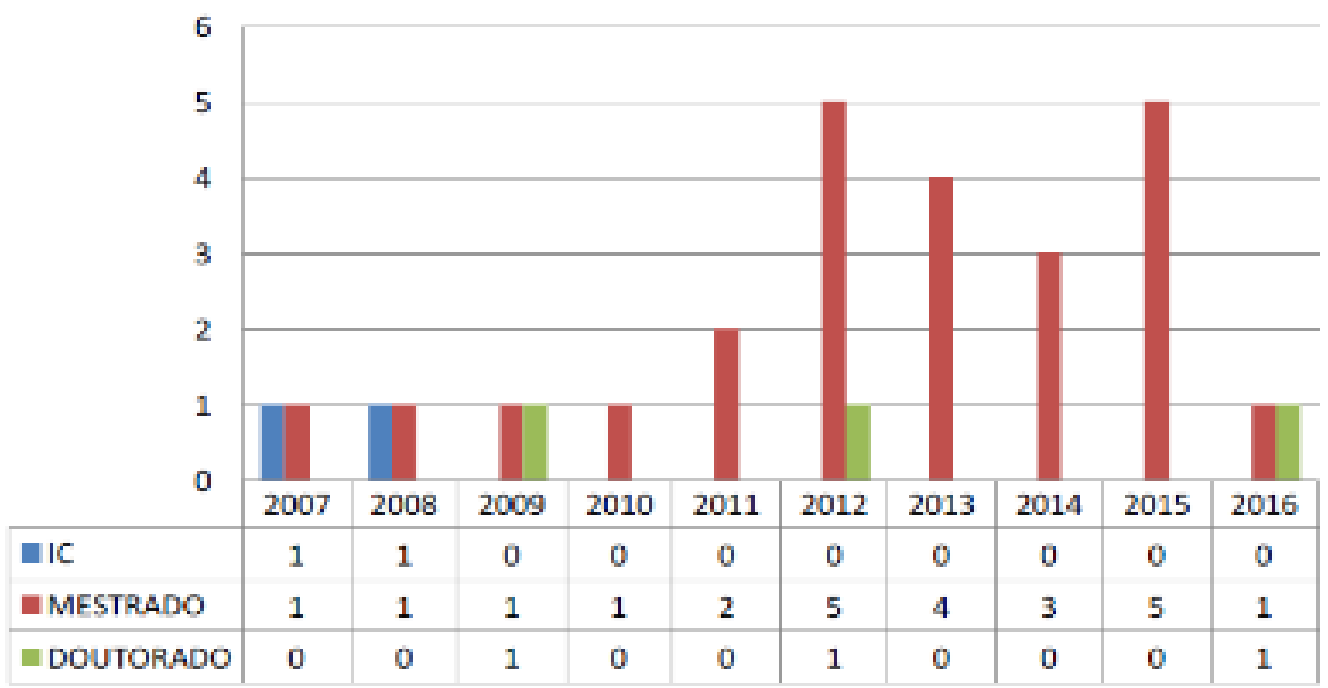

Fonte: Tuxi (2017)

Alguns aspectos devem ser avaliados quando falamos de expressões regionais e terminologia. Em "termos" não se enquadraria como "linguagem técnica ou especializada", mas como uma linguagem comum a um grupo, no caso aos "nortistas". Contudo, nosso objetivo, neste trabalho, é apenas apresentar uma parte da catalogação de sinais-termo referentes as expressões regionais e refletir sobre o porquê da incorporação no léxico sinalizado, uma vez que, em grande maioria, são expressões sonoras de confirmação entre falantes oralizados. Para isso, passemos a conhecer um pouco sobre as comunidades surdas de Boa Vista-RR e de Santarém-PA.

\section{Região norte e alguns aspectos das comunidades surdas}

O norte do Brasil, com a extensão de $3.869 .637 \mathrm{~km}^{2}$, sendo composta por sete estados: Acre, Amapá, Amazonas, Pará, Rondônia, Roraima e Tocantins. Dentre eles, no Pará e Roraima, locais de realização desta pesquisa, encontram-se uma variedade linguística regional muita rica e com alta produtividade linguística, desde em termos de formação morfológica, criatividade lexical até em termos semânticos, pragmáticos e discursivos.

Boa Vista, capital do estado de Roraima, situada à margem direita do Rio Branco, tem por limites a Venezuela, ao norte e noroeste; Guiana, ao leste; Pará, ao sudeste; e Amazonas, ao sul e oeste. A comunidade surda Boa-vistense está em processo de desenvolvimento em relação à organização político-social e principalmente educacional, o que se percebe facilmente quando em contato direto ou mesmo verificando a conjuntura educacional das escolas e das universidades. Há um número escasso de surdos no ensino superior e/ou em trabalhos que exijam grau maior de escolaridade. Por exemplo, não se tem registro de surdos professores no estado; muitos surdos com idade entre 10 e 20 anos não tem domínio da Libras e surdos que possuem graduação trabalham em tarefas inferior ao nível estudado (ANICETO JUNIOR, 2017; ARAÚJO e BENTES, 2018).

Segundo o trabalho etnográfico de Aniceto Junior (2017), a forma de organização social ainda está sendo construída. Dados numéricos são escassos ${ }^{6}$, tendo em vista a dificuldade de identificar os "surdos".

\footnotetext{
${ }^{6}$ Outros dados ainda podemos ter, a partir dos eventos organizados pela Associação Suo Jure dos Surdos de Roraima, criada em 2014. Segundo o presidente, há cerca de 66 surdos associados, incluindo seus familiares (ANICETO JUNIOR, 2017, p. 54).
} 
De acordo com o presidente da ASSJS/RR sobre o quantitativo de surdos no município de Boa Vista ainda falta um levantamento mais específico sobre a quantidade de surdos, pois segundo ele, os dados que existem sobre as pessoas surdas não são exclusivos estando computados em um mesmo indicativo pessoas que são deficientes auditivos mas que não são falantes de Libras ou que não se reconhecem como surdos. No entanto, segundo o presidente, a ASSJS/RR trabalha com a hipótese de um quantitativo entre 250 e 500 de pessoas surdas que sabem Libras em menor ou maior grau (ANICETO JUNIOR, 2017, p.54).

Em relação à educação no estado, há intérpretes de Libras no ensino regular e "professores bilíngues"”. O Centro de Atendimento ao Surdo-CAS desenvolve ações e trabalha em parceria com a associação de Surdos (inclusive no mesmo prédio). Outros, podemos citar a criação do curso Letras Libras Bacharelado em 2014, em que, em 2017, um professor surdo passou a integrar a equipe de professores do Curso e, em 2018, formou a primeira turma com uma aluna surda. Atualmente, tem dois alunos surdos matriculados (ARAÚJO e BENTES, 2018, p. 4).

Conhecida como "Pérola do Tapajós", Santarém fica situada à margem esquerda do rio tapajós. É o terceiro município mais populoso do Pará e o maior centro urbano, comercial e cultural do Oeste do Pará. É conhecida mundialmente por seus belos rios, praias e igarapés, além de suas lendas, cantos e encantos através de diversas manifestações religiosas e culturais dentre elas, destacamos o "Çairé".

A comunidade surda Santarena vem se organizando politicamente na última década, através da Associação de Tradutores e Intérpretes de Língua de Sinais do Oeste do Pará-ATILS e da Associação de Surdos de Santarém - ASUSANT, representações de fundamental importância para a concretização da acessibilidade, da equidade e da inclusão na cidade. Dentre os trabalhos desenvolvidos pela ASUSANT, a questão cultural é um dos focos maior com realizações anuais de torneios e encontros culturais.

Segundo Risomar Moraes dos Santos ${ }^{9}$, professora da rede municipal e presidente da ASTILS, a educação de surdos no munícipio está em processo de desenvolvimento. O Atendimento Educacional Especializado - AEE, para ela, é um dos pontos de partida na aquisição, entendimento e fluência da Libras como L1 e do português escrito como L2. O município conta com cinco professores surdos lotados no AEE para o ensino de Libras, às crianças surdas, contudo não há TILS contratados.

Os dois locais pesquisados são bastante diferentes quanto ao desenvolvimento político, social e educacional dos surdos. Mesmo fazendo parte da mesma região estão longe tanto geograficamente como nos "avanços" em relação aos ganhos políticos nacionais. Enquanto Santarém tem muitos surdos graduados e pós-graduados e professores surdos ensinando Libras, Boa Vista não há: ouvintes são os professores dos surdos.

Verificados alguns aspectos dessas comunidades, partimos a delimitar o caminho metodológico seguido, lembrando que o objetivo é apenas apresentar as primeiras reflexões sobre o uso, ou seja, a tradução e a incorporação das expressões regionais no léxico visual.

\section{Metodologia}

Seguindo as bases teórico-metodológicas dos Estudos da Tradução, juntamente com os estudos léxicos-terminológicos das/nas Línguas de Sinais, buscamos realizar uma análise descritiva

\footnotetext{
7 Professor pedagogo que atua como mediador, docente e tradutor-intérprete do aluno surdo nos primeiros anos do ensino fundamental. Essa função existe apenas nas escolas do Estado.

8 Festividade religiosa que acontece anualmente no município de Alter do Chão.

9 Não foram encontradas referências bibliográficas sobre a educação de surdos, em Santarém, para embasar melhor esse trabalho.

10 Há no texto o uso recorrente de aspas, seja para enfatizar, seja para citar um conceito. Usamos como recurso estilístico no texto.
} 
de três sinais-termos utilizados na sinalização das duas comunidades surdas. Para tanto, dois caminhos foram seguidos: pesquisa etnográfica e eliciação de dados, descritas abaixo.

A partir da observação etnográfica ${ }^{11}$ das comunidades surdas dos dois locais, a qual os autores têm contato há mais de dez anos, porém há pouco tempo começamos a perceber a incorporação desses sinais ao vocabulário cotidiano e perceber também que as motivações era a extrema influência dos ouvintes que utilizam demasiadamente expressões regionais. Dessa forma, a coleta de dados vem sendo realizada de forma paulatina.

Outra forma de recolha de sinais foi por eliciação. Realizada com surdos e tradutores e intérpretes de Libras de Boa Vista e de Santarém. Para tanto, foram propostas as seguintes tarefas aos surdos:

a) Primeiro perguntamos se eles conheciam as "expressões regionais" próprias das pessoas de Boa Vista/Santarém e quais saberiam dizer a "pronto o sinal".

b) Depois mostramos uma lista (Quadro 1 e 2) de palavras/expressões regionais (em português) e perguntamos se eles sabiam o significado e o sinal.

c) Os que não sabiam foram explicados em Libras.

Quadro 1 - Lista de termos/expressões apresentadas em Santarém

\begin{tabular}{|l|l|}
\hline $\begin{array}{c}\text { TERMO/EXPRESSÃO } \\
\text { SANTARÉM-PA }\end{array}$ & \multicolumn{1}{c|}{ SIGNIFICADO } \\
\hline Égua & $\begin{array}{l}\text { Vírgula do paraense, usada entre mil de mil frases ditas, e com essa expres- } \\
\text { são, ele não tem a menor chance de errar nas concordâncias }\end{array}$ \\
\hline UÁ & Credo \\
\hline Mas quando & Não se refere a data e sim a pessoa dizendo "não" \\
\hline Espia & Olha! \\
\hline Olha já & É mentira \\
\hline Aff & Ninguém merece \\
\hline TOP & Algo muito bom (pessoa ou algo) \\
\hline Borimbora & Vamos embora \\
\hline Hum, Tá Cheiroso & Hum... tá bom (Maneira Irônica) \\
\hline
\end{tabular}

Fonte: Elaboração própria ${ }^{12}$

Quadro 2 - Lista de termos/expressões apresentadas em Boa Vista

\begin{tabular}{|l|l|}
\hline \multicolumn{1}{|c|}{$\begin{array}{l}\text { TERMO/EXPRESSÃO } \\
\text { RORAIMA-RR }\end{array}$} & \multicolumn{1}{|c|}{ SIGNIFICADO } \\
\hline Maceta & Referência a algo muito grande, maior que o normal. \\
\hline Brocado & Com fome \\
\hline Cutião & $\begin{array}{l}\text { Indivíduo que abandonou a vida em sociedade na cidade grande e foi morar sozi- } \\
\text { nho, isolado de tudo e de todos. A expressão tem origem no roedor Cutia, um } \\
\text { mamífero de hábitos solitários. }\end{array}$ \\
\hline Té doido é? & o mesmo que "tú é doido, é?" \\
\hline É mermo é? & Usa-se para diversas expressões, como: Ironia e Interrogação \\
\hline Manjado & uma coisa "batida", que perde a graça por ser bastante conhecido \\
\hline Vish... & Não gostar ou ninguém merece \\
\hline Pindaíba & Pescar com a vara \\
\hline Agora bem aí! & $\begin{array}{l}\text { Expressão que se usa quando não gostamos ou não concordamos com algo que } \\
\text { alguém falou ou fez }\end{array}$ \\
\hline
\end{tabular}

11 Desde 2014, temos observado as duas comunidades (STM, BV e outras) em busca de trocadilhos, pesquisa iniciada com o projeto de extensão "Valorizando a Cultura Surda-UFOPA" (2016), ampliando-se a pesquisa de mestrado com o objetivo de coletar e traduzir "trocadilhos" próprios das comunidades surdas (ARAÚJO e BENTES, 2016; 2017; BENTES, 2018).

12 Com base no Dicionário de gírias Paraenses e no Dicionário papa-xibé, encontrado em: https://artepapaxibe.wordpress.com/dicionario/. Acesso em 15/03/18. 


\begin{tabular}{|l|l|}
\hline Bicho & $\begin{array}{l}\text { modo de referir-se à pessoa com quem conversa. Ex. Ei, bicho, que horas passo na } \\
\text { tua casa? }\end{array}$ \\
\hline Boto fé & modo de dizer que confia em algo que foi falado. \\
\hline Jaca & Referência a algo não confiável. \\
\hline Nem com nojo! & Equivale a de jeito nenhum. \\
\hline Paracatagraça! & É o mesmo que "para com a tua graça!" ou "deixa de graça!". \\
\hline Top & Algo muito bom. \\
\hline
\end{tabular}

Fonte: Elaboração própria ${ }^{13}$

Com os TILS, a metodologia foi perguntar se sabiam os sinais dos termos do quadro 1 e 2 e quais eles consideravam produtivos ${ }^{14}$ na comunidade surda. Logo, realizamos os registros de sinaistermo em pequenos vídeos. Todas as expressões foram registradas e catalogadas, dentre elas, selecionamos três de cada local para descrever. A justificativa de seleção ocorre pelos seguintes critérios: Ser indicada como produtiva no léxico sinalizado (por surdos e TILS) e ser recorrente em discursos como palestras, congressos e seminários regionais dos quais necessitam de escolhas tradutórias imediatas.

Os termos escolhidos foram:

Quadro 3 - Termos/expressões selecionadas para análise

\begin{tabular}{|c|c|}
\hline Santarém & Boa Vista \\
\hline Égua & É mermo é? \\
\hline UÁ & Tédoidoé? \\
\hline Aff! & Vish... \\
\hline \multicolumn{2}{|c|}{ Top } \\
\hline
\end{tabular}

Fonte: Próprios autores

\section{Análise dos sinais-termos das expressões regionais}

Os termos selecionados fazem parte do vocabulário cotidiano das duas comunidades ouvintes. A relação das comunidades surdas com ouvintes, principalmente, dos surdos casados com ouvintes, o que na interação diária influencia o uso desses termos, é incorporado ao vocabulário dos surdos, fazendo com que "tenham um sinal específico", ou seja, um sinal-termo, ao qual apresentaremos um a um.

Começando com os sinais produtivos na comunidade surda de Boa vista, temos o termo "É mesmo?" ou "é memo?" ou ainda "é mermo?" usado para diversas situações como para responder/confirmar algo, desconfiar e como ironianas das mais diversas ocasiões. O sinal é realizado com os mesmos parâmetros do sinal MESMO ${ }^{15}$, acrescido da expressão fácil de ironia ou dúvida mais oralização (mouthing), variando conforme a intenção e situação do interlocutor.

13 Com base nos dicionários: Linguagem informal: gírias de Roraima, encontrado em: http://conexaoug.blogspot.com/2012/06/linguagem-informal-girias-de-roraima.html e Termos regionais de Roraima, encontrado em: http://conexaoug.blogspot.com/2012/06/linguagem-informal-girias-de-roraima.html. Acesso em 25/08/18.

${ }^{14}$ Participaram três TILS mulheres, duas de Boa vista e uma de Santarém, casadas com surdos, atuam, principalmente, na interpretação em contexto educacional.

15 Disponível em www.acessibilidadebrasil.org.br. Acesso em 11/03/19. 

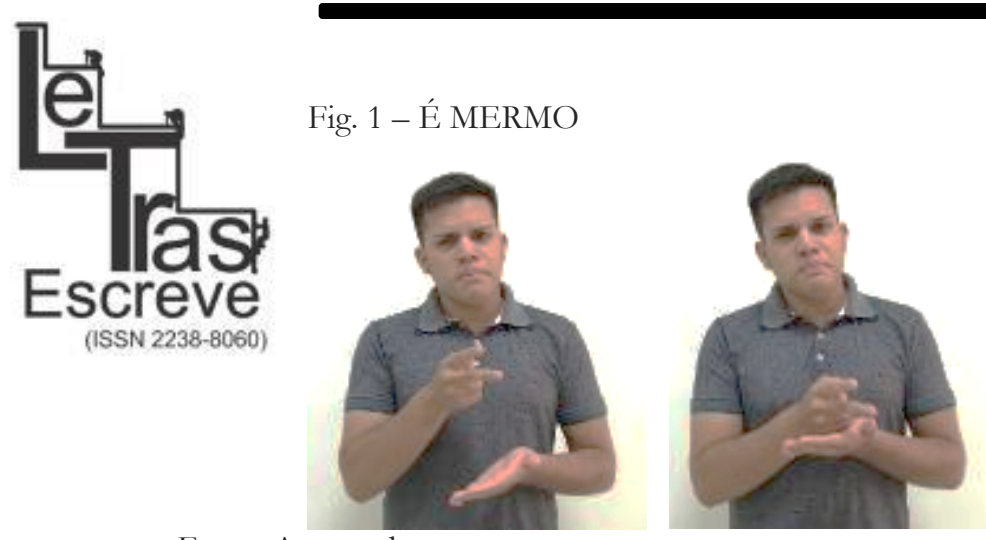

Fonte: Acervo dos autores

A expressão "Tédoidé” é usada para diversas situações como: ironia, interrogação inclusive sarcasmo. O sinal-termo, TÉDOIDÉ, segue os princípios de "É mermo", realizado com os mesmos parâmetros do sinal DOIDO.

Fig. 2 - TÉDOIDÉ
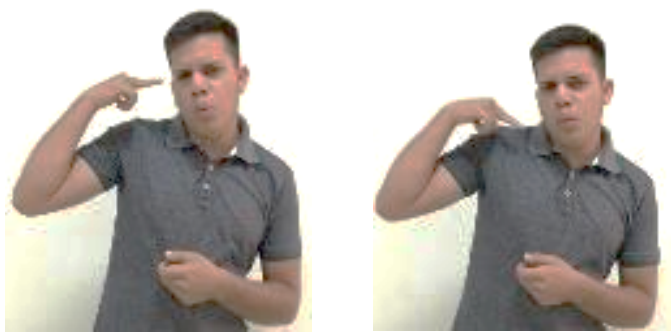

Fonte: Acervo dos autores

VIXI e EITA são usados para denotar insatisfação ou surpresa. O sinal é realizado com o dedo polegar, indicador e médio aberto, fechando em direção ao coração, o mesmo oralizando, a palavra vixi ou eita. Este sinal é conhecido como NOSSA em algumas regiões, inclusive em Santarém.

Fig. 3 - VISH/EITA
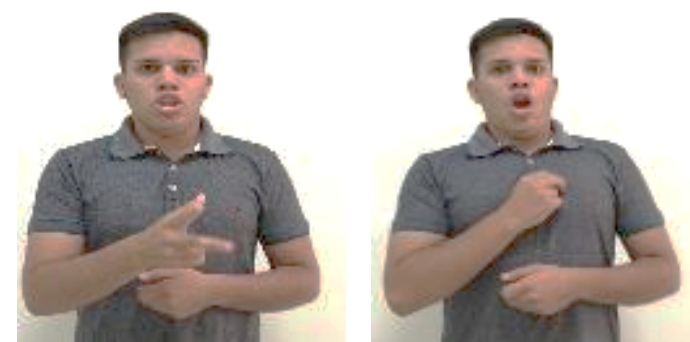

Fonte: Acervo dos autores

Égua, considerada vírgula do paraense, usada entre mil de mil frases ditas, em várias situações e com algumas mudanças (Paidégua, É-gu-á, égua bicho, égua mano, égua tu, entre outras). Tal expressão é a mais utilizada na região pelos não surdos. O sinal não corresponde a nenhum sinal do léxico nativizado da Libras e aparece com organização simultânea considerada poucos usada. $\mathrm{O}$ sinal inicia com o dedo médio encostando no queixo, depois unido com o polegar, Orientação para frente, soltando os dedos, ao mesmo tempo que oraliza a palavra. O ritmo muda conforme a intenção do falante. 
Fig. 4 - ÉGUA
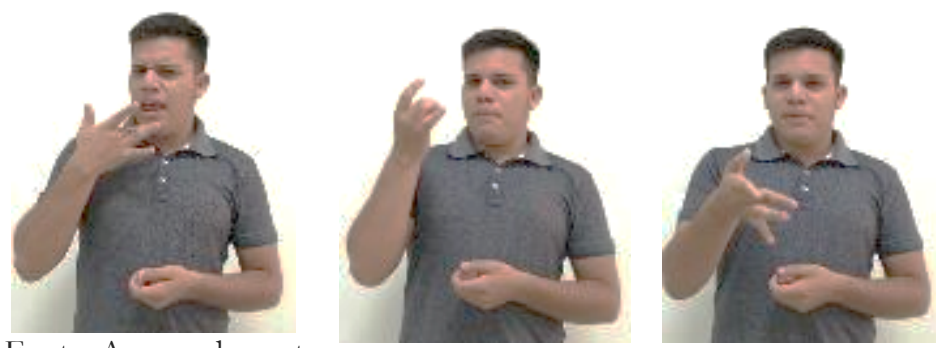

Fonte: Acervo dos autores

UÁ, muito utilizado na região Oeste do Pará, o sinal em Libras foi observado no município vizinho, Alenquer. Seu significado é o mesmo que credo, "Deus me livre" ou "sai fora". O sinal é realizado com a $\mathrm{CM}$ em $\mathrm{U}$ e posteriormente $\mathrm{A}$, com o ponto de articulação no queixo com expressão facial de não quer ou não gostar acrescido da oralização.

Fig. 5 - UÁ
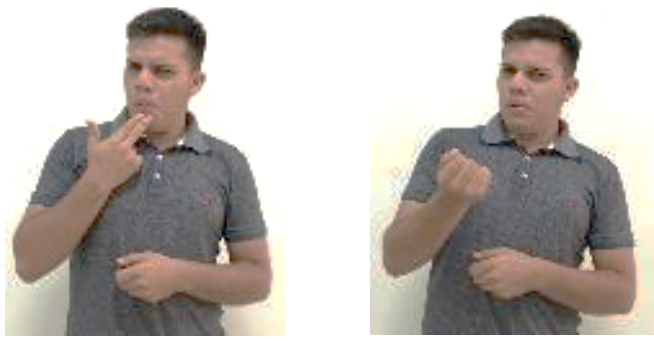

Fonte: Acervo dos autores

O termo "aff” é bastante usado na região, é um termo utilizado para intonar o mesmo sentido de "ninguém merece", sendo realizado para o sentido de insatisfação ou "impaciência". O sinal é realizado com a CM em A e posteriormente F, com o ponto de articulação em frente ao corpo, movimento em forma de meia lua e expressão facial de insatisfeito, mais oralização com f estendido (afffffffff).

Fig. $6-\mathrm{AFF}$
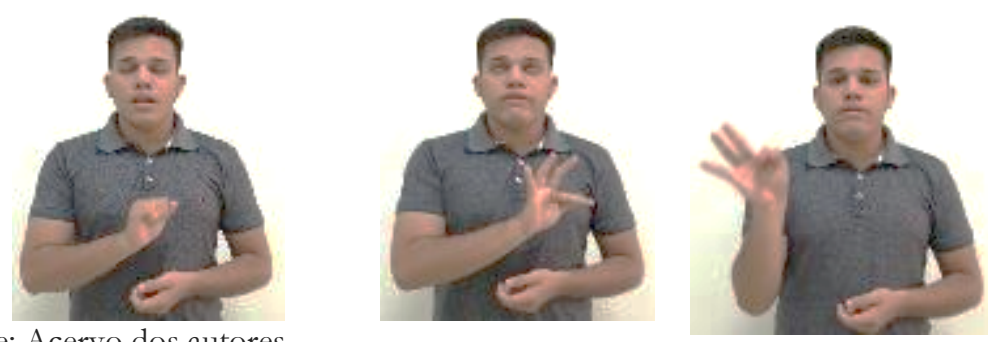

Fonte: Acervo dos autores

A palavra top é usada em ambas às comunidades, porém dentro dos registros terminológicos da Libras, essa variação é visível, haja vista que em Santarém foram registrados três sinais-termos para a mesma palavra, todavia em diferentes contextos e em diferentes sentidos. Em Boa Vista, foi encontrado um único sinal, como apresentado abaixo. 
Quadro 4 - Variações do termo TOP em Boa vista e Santarém

\begin{tabular}{|c|l|l|}
\hline \multirow{3}{*}{ STM } & TOP 1 & Sentido de pessoa inteligente \\
\cline { 2 - 3 } & TOP 2 & Pessoa metida \\
\cline { 2 - 3 } & TOP 3 & $\begin{array}{l}\text { Formal, algo que está muito bom e é quase impossível ser modificado, tam- } \\
\text { bém usado no sentido de pessoa muito metida. }\end{array}$ \\
\hline \multirow{2}{*}{ BV } & TOP 4 & Usado para todas as situações descritas acima \\
\cline { 2 - 2 } & TOP 5 & \\
\hline
\end{tabular}

Fonte: Próprios autores

Fig. 7 - TOP1- sentido de pessoa inteligente
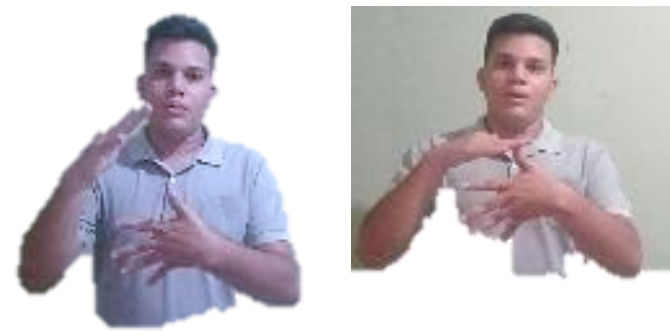

Fonte: Acervo dos autores

Fig. 8 - TOP 2 - Pessoa metida
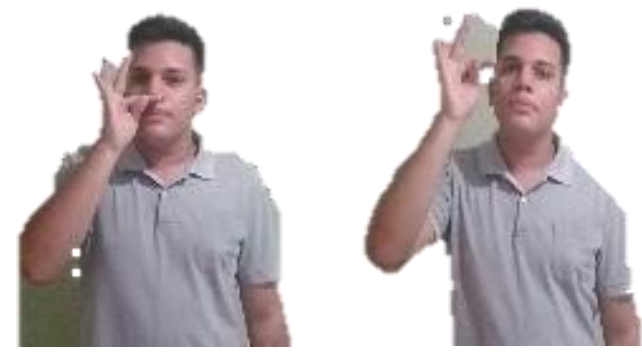

Fonte: Acervo dos autores

Fig. 9 - TOP 3 - Formal, algo que está muito bom e é quase impossível ser modificado, também usado no sentido de pessoa muito metida.
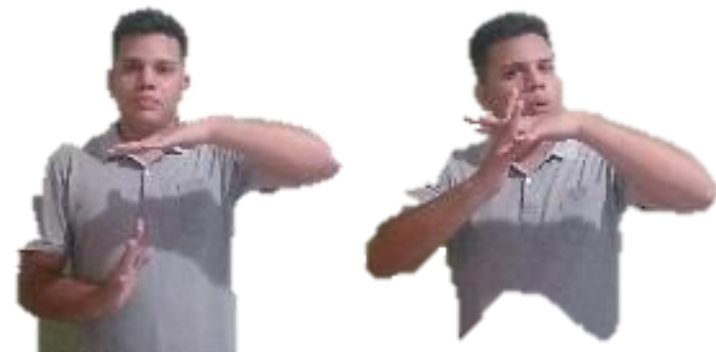

Fonte: Acervo dos autores

Fig. 10 - TOP 4 - Usado para todas as situações descritas acima

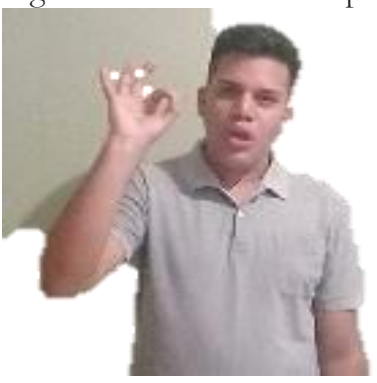

Fonte: Acervo dos autores 
Fig. 11 - TOP 5 - Usado para todas as situações descritas acima

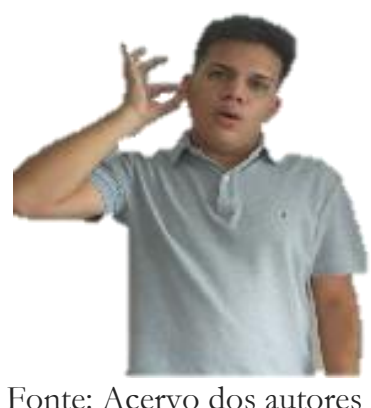

Nos sinais coletados, percebemos que usam uma espécie de "tradução literal", recorrendo ao sinal correspondente à palavra em português, porém acrescentando expressões faciais e a oralização da palavra.

\section{Considerações finais}

Foi apresentado neste trabalho o recorte de uma pesquisa maior sobre a tradução de expressões regionais para a Libras, em duas localidades do norte do Brasil. A pesquisa teve por objetivo catalogar e registrar os sinais-termos das expressões regionais próprias dessas e das traduções feitas para as expressões das comunidades ouvintes, além de refletir sobre a questão sociolinguística destas comunidades que atravessa e é atravessada por diversas culturas.

Mesmo com a incipiência dos dados, verificamos que há uma forte influência de ouvintes sinalizantes que fazem parte dessas comunidades (como cônjuges, pais e parentes e/ou outras pessoas que sabem Libras) para que as produções dessas traduções circulem e façam parte do vocabulário cotidiano entre surdos-surdos e principalmente entre surdos-ouvintes.

Em Boa vista, a maioria dos surdos utilizam a oralização dos sinais para "ajudar" na comunicação com os ouvintes que não sabem Libras. Ao longo do tempo, fomos percebendo o quanto os surdos desejavam saber o que significava cada expressão e como rapidamente foram sendo incorporadas na conversação cotidiana de surdos, principalmente, dos que tinham resquícios de audição, os surdos oralizados. Isso em Boa vista onde a comunidade surda ainda caminha a passos lentos em direção a uma emancipação política e linguística.

Cabe lembrar que este trabalho apenas considerou parte dos termos coletados de uma pesquisa maior. Aqui, apenas refletimos o porquê dessas expressões serem inseridas no léxico das duas comunidades. O registro dos sinais vistos está sendo realizado para posterior divulgação, a fim de auxiliar a preencher a lacuna de estudos sobre esses termos nas LSs.

\section{Referências}

AUBERT, Francis. As (In)fidelidades da Tradução: servidões e autonomia do tradutor. Campinas: Unicamp, 1994.

ANICETO JÚNIOR, Dalcides dos Santos. Por Uma Etnografia de Pessoas Surdas na Cidade de Boa Vista: construção social de identidade nos discursos surdos. Trabalho de Conclusão de Curso (Antropologia), Universidade Federal de Roraima, Boa Vista, 2017.

ARAÚJO, Paulo Jeferson Pilar; BENTES, Thaisy. Jogos de sinais híbridos e empréstimos do português na Língua Brasileira de Sinais-Libras. Revista LinguíStica, Rio de Janeiro, v. 13, n. 3, p. 150-173, 2017.

ARAÚJO, P. J. P.; BENTES, T. Contatos linguísticos e bilinguismo uni e bimodal entre a Libras e a LSV em Roraima. Revista de Divulgação Científica em Língua Portuguesa, Linguística e Literatura. Ano 14, n.23, $2^{\circ}$ Semestre,- 2018. 
BENTES, Thaisy. A Tradução de Trocadilhos em Alice no País das Maravilhas para a Língua Brasileira de Sinais - LIBRAS. Brasília, 2018. 146 f. Dissertação (Mestrado em Estudos da Tradução) - Programa de Pós-Graduação em Estudos da Tradução (POSTRAD), Universidade de Brasília (UnB), Brasília, 2018.

FAULSTICH, Eunildes; ROCHA, S. L. R. A função pragmática do contexto linguístico em obras lexicográficas e terminográficas. In: ZINGLÉ, H. (Org.). Travaux du LILLA. Nice: Faculté dês Lettres, Arts et Sciences Humaines de l'Université de Nice-Sophia Antipolis, 1997. p. 23-32.

Para gostar de ler um dicionário. In: RAMOS, C. M. A et al. (Org.). Pelos Caminhos da Dialetologia e da Sociolinguística: entrelaçando saberes e vida - homenagem a Socorro Aragão. São Luís: EdUFMA, 2010.

Características conceituais que distinguem o que é de para que serve nas definições de terminologias científica e técnica. In: ISQUERDO, A. N; DAL CORNO, G. O. M. (Orgs.). $\boldsymbol{A} \boldsymbol{s}$ Ciências do Léxico: lexicologia, lexicografia, terminologia. Vol. VII. Campo Grande, MS: Ed. UFMS, 2014.

FAULSTICH, Eunildes. Especificidades semânticas e lexicais: a criação de sinais-termo na língua de sinais brasileira. In: NADIN, Odair Luiz; FERREIRA, Anise de Abreu Gonçalves; FARGETTI, Cristina Martins. (Orgs.). Léxico e suas Interfaces: Descrição, Reflexão e Ensino. Araraquara/SP: Cultura Acadêmica, 2016.

FARIA-NASCIMENTO, S. P. Representações Lexicais da Língua de Sinais Brasileira: Uma Proposta Lexicográfica. 2019. 119 f. Dissertação (Mestrado em Linguística) - Programa de PósGraduação em Linguística, Universidade de Brasília (UnB), Brasília, 2019.

FELTEN, Eduardo Felipe. Glossário Sistêmico Bilíngue Português-Libras de Termos da História. Dissertação (Mestrado em Linguística) - Universidade de Brasília, Brasília, 2016.

TUXI, Patrícia. A Terminologia na Língua de Sinais Brasileira: proposta de organização e de registro de termos técnicos e administrativos no meio acadêmico em glossário bilíngue. 2017. 278f. Tese (Doutorado em Linguística) - Universidade de Brasília, Brasília, 2017.

SOUZA, K. M. de; FERNANDES, L. A.; XAVIER, V. R. D. Do léxico erótico-obsceno: cotejo lexicográfico entre variantes na Língua Portuguesa e na Libras. Revista Diálogos (RevDia), Dossiê temático "Educação, Inclusão e Libras, v. 6, n. 1, jan.-abr., 2018. http:// periodicoscientificos.ufmt.br/ojs/index.php/revdia.

VALE, L. M. A Importância da Terminologia para Atuação do Tradutor e Intérprete de Língua de Sinais Brasileira: proposta de glossário de sinais-termo do processo judicial eletrônico. 2018. 119 f. Dissertação (Mestrado em Estudos da Tradução) - Programa de Pós-Graduação em Estudos da Tradução (POSTRAD), Universidade de Brasília (UnB), Brasília, 2018. 